\title{
Assessment of Monthly Rain Fade in the Equatorial Region at C \& Ku-band using MEASAT-3 Satellite Links
}

\author{
Y. A. Ahmad ${ }^{1}$, N. H. S. Suhaimi ${ }^{2}$, A.F. Ismail ${ }^{1}$, K. Badron ${ }^{1}$ \\ ${ }^{I}$ Faculty of Engineering, International Islamic University Malaysia (IIUM) \\ ${ }^{2}$ Science and Technology Research Institute of Defence (STRIDE) \\ yasser@iium.edu.my; sabrina.suhaimi@stride.gov.my; af_ismail@iium.edu.my; \\ khairayu@iium.edu.my;
}

\begin{abstract}
Summary. $C \&$ Ku-band satellite communication links are the most commonly used for equatorial satellite communication links. Severe rainfall rate in equatorial regions can cause a large rain attenuation in real compared to the prediction. ITU-R P. 618 standards are commonly used to predict satellite rain fade in designing satellite communication network. However, the prediction of ITU-R is still found to be inaccurate hence hinder a reliable operational satellite communication link in equatorial region. This paper aims to provide an accurate insight by assessment of the monthly $C \& \mathrm{Ku}$-band rain fade performance by collecting data from commercial earth stations using $C$ band and Ku-band antenna with $11 \mathrm{~m}$ and $13 \mathrm{~m}$ diameter respectively. The antennas measure the $C \& K u$-band beacon signal from MEASAT-3 under equatorial rain conditions. The data is collected for one year in 2015. The monthly cumulative distribution function is developed based on the 1-year data. RMSE analysis is made by comparing the monthly measured data of $C$-band and Ku-band to the ITU-R predictions developed based on ITU-R's P.618, P.837, P.838 and P.839 standards. The findings show that Ku-band produces an average of 25 RMSE value while the C-band rain attenuation produces an average of 2 RMSE value. Therefore, the ITU-R model still under predicts the rain attenuation in the equatorial region and this call for revisit of the fundamental quantity in determining the rain fade for rain attenuation to be re-evaluated.
\end{abstract}

Keywords: Satellite Communication Link, Rain Attenuation, C- Band, Ku-Band, Equatorial Region.

\section{$1 \quad$ Introduction}

In microwave satellite communication, frequencies such as C-band, X-band, Ku-band and Ka-band are primarily utilised for satellite communication applications such as telecommunications, broadcasting, and data communications for broadcasters, Internet service providers (ISPs), governments, the military, and other sectors. C and Ku-band are commonly used in the equatorial region for satellite communication link. However, equatorial regions experience severe rainfall rate. Thus, rain-induced attenuation is a big challenge for higher satellite frequencies application leading to loss of signal. The consequences of rain attenuation include loss of signal strength at the receiver and wastage of transmission power in order to overcome the loss of signal [1]. Rain attenuation prediction has become the key step as designing satellite communication links is very important in term of cost and time effective.

Rain attenuation or rain fade refers to the signal amplitude depletion due to rainfall in the event where the satellite signal is disturbed from reaching its destination, resulting in slow, inconsistent or distorted transmissions [2]. The rainfall scatters and absorbs the radio wave. Higher frequency radio waves will have a shorter wavelength, and shorter wavelengths are more 
severely affected by absorption and scattering of raindrops [3-4]. Thus, the rain fade margin is an important parameter that must be emphasised to overcome signal degradation due to heavy rainfall, such as in equatorial regions [5].

In order to mitigate rain attenuation, the ITU-R has developed a method for predicting attenuation due to rain along a slanted path [6]. Numerous studies also claimed that the ITU-R model has not been able to accurately predict rain fade for tropical regions [7-9]. Despite having rain attenuation measurements reported in the tropical region, the data are too scarce and limited to produce accurate rain attenuation models particularly and specific attenuation models [10]. In a feasibility analysis for next-generation satellite conducted for Indonesia using the ITU-R P618 standards, [11] rejected the use of $\mathrm{Ku} / \mathrm{Ka}$-band for satellite system due to large unpractical rain fade margin requirement. Instead, a $\mathrm{C} / \mathrm{Ku}$-band pair is proposed for the next generation satellite system. Thus, this article aims to provide an empirical evaluation of rain fade in terms of cumulative distribution function (CDF) using the MEASAT -3 satellite links and its commercial earth stations situated in the equatorial region, Malaysia. The finding in this article also aims to provide accurate insight into the performance of rain fade for $\mathrm{C}$ and $\mathrm{Ku}$ band in an equatorial climate.

The climate in Malaysia is categorized as equatorial as the weather is hot and humid throughout the year but is also considered to be tropical as rainfall also occurs throughout the year [12]. A tropical region climate has two seasons, dry and wet season. The dry season has an average rainfall characteristic of about $50 \mathrm{~mm} / \mathrm{hr}$ where the wet season has a very high rainfall rate [13,14]. On the other hand, the equatorial region has the same features as the tropical region in terms of rain formation and raindrop sizes. The equatorial region however has a hot and wet season throughout the year with heavy rainfall usually occurs in the afternoon throughout the year [13,14]. In Malaysia, a country with an equatorial mixed with tropical climate has a very high rainfall rate that can exceed $200 \mathrm{~mm} / \mathrm{hr}$ [15].

\section{$2 \quad$ Empirical measurement set up}

\subsection{Measat-3 satellite link parameters}

The Measat-3 employs $\mathrm{C} \& \mathrm{Ku}$-band links. The C-band and Ku-band beacons are used to measure the rain fade during rainy days. The $\mathrm{C}$-band and Ku-band beacons are on board MEASAT-3 satellites located in an orbit at $91.5^{\circ} \mathrm{E}$. The frequencies for the beacons are 4.198 $\mathrm{GHz}$, and $12.201 \mathrm{GHz}$ for $\mathrm{C}$-band, and $\mathrm{Ku}$-band respectively. The elevation angle for MEASAT-3 satellite is 77.5 degree.

\subsection{Earth station system}

The C-band earth station is located in MEASAT Teleport and Broadcast Centre, while the Ku-band earth station is located in the MEASAT Broadcast Network (ASTRO) Broadcast Centre. Both centres are adjacent to each other and located in Cyberjaya, Malaysia and having a latitude and longitude of $\left(2.935^{\circ} \mathrm{N}, 101.658^{\circ} \mathrm{E}\right)$. The $4.198 \mathrm{GHz} \mathrm{C}$-band beacon signals from Measat 3 is received by is an $11.1 \mathrm{~m}$ diameter Cassegrain type C-band antenna located at the MEASAT teleport. The $11.1 \mathrm{~m}$ antenna system consists of a Low Noise Amplifier (LNA) with a Gain over Temperature $(\mathrm{G} / \mathrm{T})$ performance of $33 \mathrm{~dB} / \mathrm{K}$. The $\mathrm{Ku}$-band antenna is a $13.1 \mathrm{~m}$ diameter Cassegrain type antenna. The size is bigger than the $\mathrm{C}$-band to cater a larger bandwidth for Broadcasting Satellite Services (BSS) as well as to ensure reliable fade margin on the uplink during rain. The Ku-band antenna points to MEASAT-3 satellite. The $13.1 \mathrm{~m}$ antenna system consists of an LNA with a G/T performance of $40.5 \mathrm{~dB} / \mathrm{K}$.

The beacons received by the antennas are amplified by the LNA and then downconverted to $1.5 \mathrm{GHz}$ as an input to the tracking receiver. The tracking receiver is a Digital 
Signal Processing (DSP) based receiver developed for satellite tracking and uplink power control. It accepts wideband RF inputs, select frequency and digitally processes the selected signal using Direct Digital Synthesizer (DDS) technique to facilitate $1 \mathrm{kHz}$ frequency resolution. At the same time, a rain gauge data with similar time period is obtained from the Department of Irrigation and Drainage Malaysia (DID) located nearby the earth stations. The DID rain gauge is a remote sensing tipping bucket type. It is a meteorological standard rain gauge with a portable, rugged and lightweight unit that is able to continuously measure the volume of rainfall by using a twin bucket type hence providing high accuracy and measurement reliability. Each tip of the bucket is able to measure $0.5 \mathrm{~mm}$ of rainfall. The data is recorded in one-minute intervals, sent via modem to the internet and then made available at the DID portal.

\section{Monthly CDF for C-band rain attenuation}

The measurement and analysis of rain attenuation at C-band at the frequency of 4.198 $\mathrm{GHz}$ is discussed in this section. Fig. 1 displays the monthly cumulative distribution for C-band rain attenuation. The rain attenuation data is based on the observation from MEASAT-3A Cband transponder. The data were collected from the MEASAT Cyberjaya earth station from the months of January to November in 2015. The data for the month of December was not available due to maintenance work at the earth station. Therefore, it was extrapolated from the rest of the months in order to produce its cumulative distribution function. Rain attenuation varies on a monthly basis from around $0.9 \mathrm{~dB}$ to $3 \mathrm{~dB}$ depending on the rainfall rate. The CDF results are presented in time exceedance form. From Fig.1, the highest rain attenuation measured at time exceedance of $0.01 \%$ was at $3.8 \mathrm{~dB}$ for the month of May 2015. The lowest rain attenuations at time exceedance of $0.01 \%$ are $1.5 \mathrm{~dB}$ in October 2015. The result shows that $\mathrm{C}$-band frequencies less affected by rain, since the the max rain attenuation is below $5 \mathrm{~dB}$ which can be neglected.

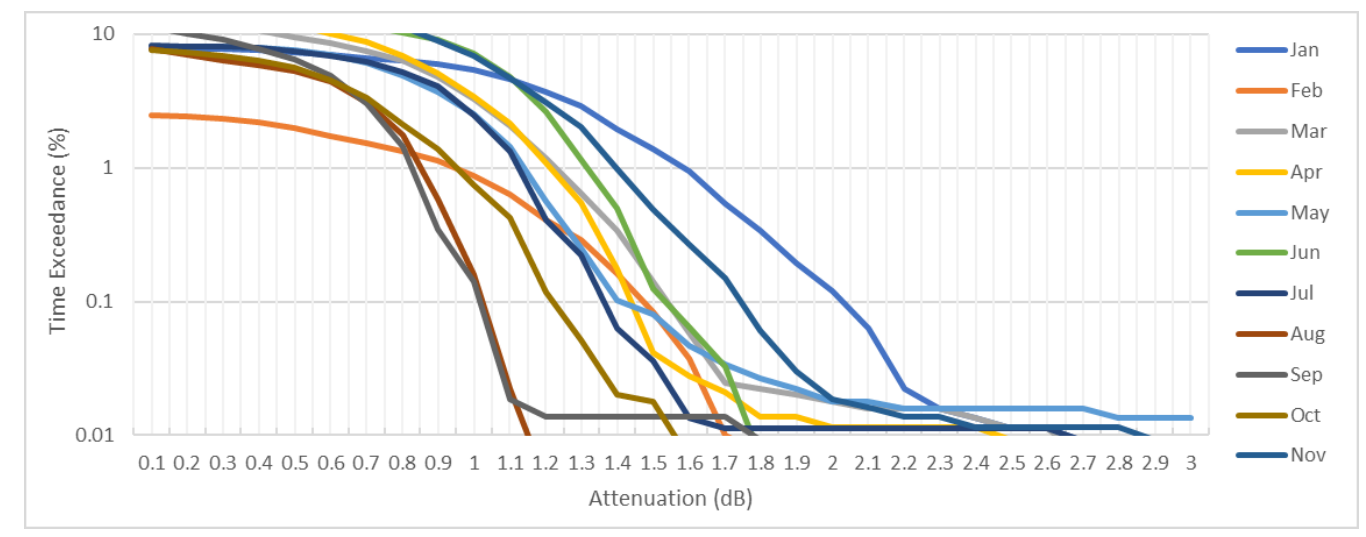

Fig. 1. Monthly CDF for C-band rain attenuation

\section{$4 \quad$ Monthly CDF for Ku-band rain attenuation}

The measurement of Ku-band rain attenuation results in terms of the cumulative distribution function is presented in this section. The Ku-band rain attenuation data were obtained from the MEASAT Broadcast Network (ASTRO) earth stations located in Cyberjaya. The Ku-band rain attenuation data consist of data from January to December for the year 2015 . The rain attenuation was measured based on the Ku-band beacon signal at a frequency of 12.201 $\mathrm{GHz}$ originating from MEASAT 3A transponder. 2 provides the measurement of rain attenuation for $\mathrm{Ku}$-band in terms of $\mathrm{CDF}$ for the year 2015. The measured attenuations for 
January, March, May and December in the year 2015 possessed higher attenuation than the other months. Rain attenuation at $0.01 \%$ exceedance for January, March, May and December are $42 \mathrm{~dB}, 43 \mathrm{~dB}, 40 \mathrm{~dB}$ and $39 \mathrm{~dB}$, respectively. In 2015, the lowest attenuation recorded at $0.01 \%$ of time exceedance was $7 \mathrm{~dB}$ during August. Based on the measurement, the rain attenuation varies greatly between $7 \mathrm{~dB}$ to $44 \mathrm{~dB}$ depending on the rainfall rate condition.

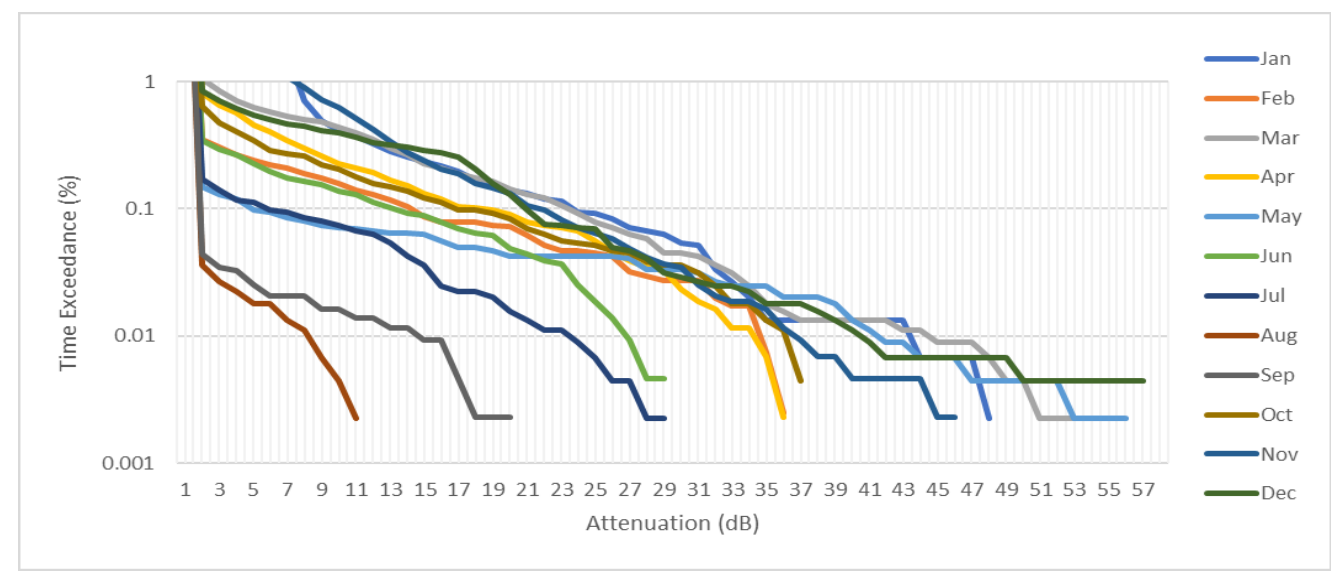

Fig. 2. Monthly $\mathrm{CDF}$ for $\mathrm{Ku}$-band rain attenuation

\section{$5 \quad$ Monthly Rain Fade Assessment}

Table 1 and Table 2 provide a comparison of the rainfall rate on a monthly basis from the DID rain gauge and rain attenuation based on the monthly CDF. The "NA" symbol in the table refers to "Not Available" since no attenuation was associated with the time exceedance value. It can be observed that the rain attenuation varies according to the rainfall rate where a lower rainfall rate produces lower rain attenuation such as May August experience smaller rain attenuation due to lower rainfall rate for both $\mathrm{C}$ band and $\mathrm{Ku}$ band. However, the rain attenuations in $\mathrm{Ku}$-band are significantly larger than in C-band.

Table 1. Monthly CDF for rainfall rate and C-band rain attenuation

\begin{tabular}{|l|l|l|l|l|l|}
\hline Months & Rain rate at & \multicolumn{5}{|l|}{ C-band Monthly CDF (dB) } \\
\cline { 3 - 6 } & Ro.01\% $(\mathrm{mm} / \mathrm{hr})$ & $\mathbf{0 . 0 1}$ & 0.03 & 0.1 & 0.3 \\
\hline Jan & 90 & 2.6 & NA & 2 & 1.8 \\
\hline Feb & 102 & 1.7 & 1.6 & 1.5 & 1.3 \\
\hline Mar & 102 & 2.6 & NA & 1.5 & 1.4 \\
\hline Apr & 120 & 2.4 & 1.6 & NA & NA \\
\hline May & 132 & 3.8 & 1.7 & 1.4 & 1.3 \\
\hline Jun & 103 & 1.8 & 1.7 & 1.5 & NA \\
\hline Jul & 73 & 2.6 & 1.5 & NA & NA \\
\hline Aug & 54 & NA & NA & 1 & NA \\
\hline Sep & 61 & 1.7 & NA & 1 & 0.9 \\
\hline Oct & 145 & 1.5 & NA & 1.2 & NA \\
\hline Nov & 180 & 2.8 & 1.9 & 1.7 & 1.6 \\
\hline Dec & 138 & 2.7 & 2.1 & 1.9 & 1.7 \\
\hline
\end{tabular}

Table 2. Monthly $\mathrm{CDF}$ for rainfall rate and $\mathrm{Ku}-$ band rain attenuation

\begin{tabular}{|l|l|l|l|l|l|}
\hline Months & Rain rate at & \multicolumn{5}{|l|}{ Kul-band Monthly CDF (dB) } \\
\cline { 3 - 6 } & Ro.01\% (mm/hr) & 0.01 & 0.03 & 0.1 & 0.3 \\
\hline Jan & 90 & 41.9 & 30.9 & 21.9 & 11.1 \\
\hline Feb & 102 & 32.9 & 25.7 & 12.6 & 1.6 \\
\hline Mar & 102 & 43.3 & 31.9 & 22.1 & 11.5 \\
\hline Apr & 120 & 32.8 & 27.8 & 16.6 & 6.4 \\
\hline May & 132 & 39.7 & 29.6 & 3.4 & NA \\
\hline Jun & 103 & 24.8 & 21.8 & 11.5 & 1.2 \\
\hline Jul & 73 & 22.4 & 13.9 & 4.4 & NA \\
\hline Aug & 54 & 7.3 & 0.8 & NA & NA \\
\hline Sep & 61 & 12.6 & 2.6 & NA & NA \\
\hline Oct & 145 & 34.8 & 29.7 & 15.4 & 4.2 \\
\hline Nov & 180 & 34.5 & 29.2 & 19.9 & 12.2 \\
\hline Dec & 138 & 38.6 & 28.4 & 19.2 & 13.2 \\
\hline
\end{tabular}

To assess the rain attenuation, the $\mathrm{C} \& \mathrm{Ku}$-band rain attenuations were compared to the ITU-R predictions [6,16-18]. Root Mean Square Error (RMSE) analysis is used to compare the ITU-R rain fade prediction with the monthly $\mathrm{CDF}$ of $\mathrm{C}$-band and $\mathrm{Ku}$-band. Fig. 3 shows the RSME analysis in graphical format for $\mathrm{C} \& \mathrm{Ku}$-band in the equatorial region. 


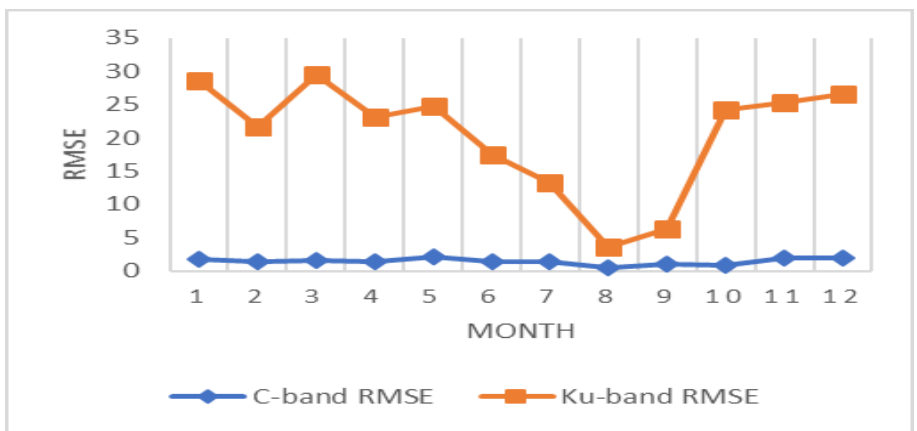

Fig. 3. RMSE for C \& Ku-band for Monthly Rain Attenuation in 2015

Based on the analysis, it can be observed that the Ku-band has a much higher RMSE than the C-band. There is slight underestimation for $\mathrm{C}$-band rain attenuation prediction but on average the RMSE is small. For Ku-band, the RMSE value in the month of August and September in the year 2015 are small. This is due to the lower rainfall rate recorded during both August and September 2015, $54 \mathrm{~mm} / \mathrm{hr}$ and $61 \mathrm{~mm} / \mathrm{hr}$ respectively. However, for other months, the RMSE for Ku-band are very high. It shows that the ITU-R prediction greatly underestimates the prediction for Ku-band link in the equatorial region. ITU-R prediction for C-band shows a good estimation with the measured value. There are a few research that attempts to improve the correction factors of the ITU-R $[7,19]$ to obtain a better prediction for higher frequencies. This result shows that the monthly rainfall rate values vary widely hence the rain attenuation also varies. Instead of adjusting the correction factors to suit equatorial-tropical region, fundamental quantity such as the specific attenuation and rainfall rate for equatorial region should be reexamined.

\section{Conclusion}

The analysis conducted in this article is based on data measurement of an industrialgrade earth station thus providing an accurate insight of the rain fade value. The equatorial climate has a well-distributed rainfall mixed with tropical monsoon. The monthly assessment provides a better understanding of the behaviour of rain attenuation on a monthly basis that can be suited with the rainy seasons.

This analysis indicates that the rain attenuation at $\mathrm{Ku}$-band satellite link is very severe and the ITU-R P618 still under predicts the rain attenuation in the equatorial region. C-band rain attenuation prediction from the ITU-R is still acceptable. However, at a time exceedance smaller than $0.01 \%$ the $\mathrm{C}$ band rain attenuation can sharply increase due to very high rainfall rate. This article also calls for the rainfall rate and specific attenuation for equatorial region to be re-examined.The study of the new specific attenuation for equatorial will be further analysed.

\section{$7 \quad$ Acknowledgements}

The authors would like to express gratitude to MEASAT Satellite System Sdn. Bhd. (MEASAT) MEASAT Broadcast Network System Sdn Bhd (ASTRO) and the Department of Irrigation and Drainage, Malaysia for the collaboration in this research project. 


\section{References}

1. Islam R, Chebil J, Khalifa O O, Khan S, Dao H and Zyoud A 2010 Effect of Frequency on Fade Slope Based on Rain Attenuation Data Measured in Malaysia 11-3

2. Ismail A F and Watson P A 2002 Characteristics of fading and fade countermeasures on a satellite-Earth link operating in an equatorial climate, with reference to broadcast applications IEE Proc. - Microwaves, Antennas Propag. 147369

3. Vivekanandan J, Zhang G and Politovich M K 2000 Estimation of cloud droplet size and liquid water content using dual-wavelength radar measurements International Geoscience and Remote Sensing Symposium (IGARSS) vol 5 pp 1813-6

4. Kesavan U, Islam M R, Abdullah K and Tharek A R 2015 Rain attenuation prediction for higher frequencies in microwave communication using frequency scaling technique Proc. - 5th Int. Conf. Comput. Commun. Eng. Emerg. Technol. via Comp-Unication Converg. ICCCE 2014 217-9

5. Nuroddin A C M, Ismail A F, Badron K, Zulkurnain N F, Ismail M and Salim H 2013 Rain induced attenuation studies using RazakSAT space-earth links Int. Conf. Sp. Sci. Commun. Iconsp. 402-6

6. ITU-R P.618-13 2017 Propagation data and prediction methods required for the design of Earth-space telecommunication systems Recomm. ITU-R P.618-13 12 1-24

7. Yeo J X, Lee Y H and Ong J T 2009 Modified ITU-R slant path rain attenuation model for the tropical region ICICS 2009 - Conf. Proc. 7th Int. Conf. Information, Commun. Signal Process. 40-3

8. Sujimol M R, Acharya R, Singh G and Gupta R K 2015 Rain attenuation using Ka and Ku band frequency beacons at Delhi Earth Station Indian J. Radio Sp. Phys. 44 45-50

9. Cuervo F, Schönhuber M, Capsoni C, Yin L H, Jong S L, Din J Bin and Martellucci A 2016 Ka-band propagation campaign in Malaysia - First months of operation and site diversity analysis 2016 10th Eur. Conf. Antennas Propagation, EuCAP 2016

10. S. Das 2010 Rain Attenuation Modelling in the 10-100 GHz Frequency using Drop Size Distributions for Different Climatic Zones in Tropical India 25 211-24

11. Widjanarko D I and Gunawan D 2017 A hybrid C/Ku-band high throughput satellite systems as an optimal design for Indonesia Proceedings - International Conference on Signals and Systems, ICSigSys 2017 pp 168-74

12. Tang K H D 2019 Climate change in Malaysia: Trends, contributors, impacts, mitigation and adaptations Sci. Total Environ. $6501858-71$

13. Wang B, LinHo, Wang B and LinHo 2002 Rainy Season of the Asian-Pacific Summer Monsoon* J. Clim. 15 386-98

14. Chang C-P, Wang Z, McBride J, Liu C-H, Chang C-P, Wang Z, McBride J and Liu C-H 2005 Annual Cycle of Southeast Asia-Maritime Continent Rainfall and the Asymmetric Monsoon Transition J. Clim. 18 287-301

15. N. H. K and Din J 2005 Rainfall Rate from Meteorological Radar Data for Microwave Applications in Malaysia 2005 13th IEEE International Conference on Networks Jointly held with the 2005 IEEE 7th Malaysia International Conf on Communic vol 2 (IEEE) pp 1008-10

16. ITU-R P.838-3 2005 Specific attenuation model for rain for use in prediction methods Recomm. ITU-R P.838-3 1-5

17. P.839-4 I-R 2013 Rain height model for prediction methods P Series Radiowave propagation

18. ITU-R P.837-7 2017 Characteristics of precipitation for propagation modelling P Series Radiowave propagation Radiowave Propag. 6

19. Yussuff A I O and Khamis N H H 2013 Modified ITU-R Rain Attenuation Prediction Model for a Tropical Station J. Ind. Intell. Inf. 1 155-9 